\title{
Impact of the COVID-19 pandemic on the pediatric population with acute appendicitis: Experience at a general, tertiary care hospital
}

\author{
Carolina Percul, M.D. ${ }^{a}$, Marion Cruz, M.D. ${ }^{a}$, Alejandra Curiel Meza, M.D. ${ }^{a}$, \\ Germán González, M.D. ${ }^{a}$, Luciana Lerendegui, M.D. ${ }^{a}$, María C. Malzone, M.D. ${ }^{a}$, \\ Daniel Liberto, M.D. ${ }^{a}$, Pablo Lobos, M.D. ${ }^{a}$, Benjamin E. Imach, M.D. ${ }^{a}$, \\ Juan M. Moldes, M.D. ${ }^{a}$ and Julián Llera, M.D. ${ }^{a}$
}

\begin{abstract}
Introduction. Appendicitis is the leading cause of surgical acute abdomen in pediatrics. During the COVID-19 pandemic, managementstrategies were reassessed and the number of visits to the emergency department dropped down, which may be associated with delayed diagnoses and complications. The objective of this study was to analyze the impact of the pandemic on children with acute appendicitis.

Methods. Analytical, retrospective, comparative study of pediatric patients with acuteappendicitis in the 5 months of COVID-19 lockdown versus the same period in the previous year. Incidence, clinical data, stage, surgical approach, and complications were analyzed.

Results. The total number of appendicitis cases went down by $25 \%(n=67$ versus $n=50$ in 2020$)$. The mean time to consultation was 24 hours in both periods $(p=0.989)$. The incidence of peritonitis was $44 \%(\mathrm{n}=22)$ versus $37 \%$ $(\mathrm{n}=22)(p=0.22)$ in 2019. No differences were observed in terms of appendicitis stage based on surgery reports. In 2019, all surgeries were laparoscopic; while in 2020, only $42 \%(n=21)$. The incidence of complications was $6 \%$ versus $7.5 \%$ in the previous period ( $p=0.75)$. One patient was COVID-19 positive.

Conclusion. Although in our population the number of appendicitis cases dropped down, consultation was not delayed. The greater impact was associated with the reformulation of management strategies, in which the laparoscopic approach is avoided to reduce virus transmission.

Key words: appendicitis, COVID-19, coronavirus,
\end{abstract} pandemic, child.

http: / / dx.doi.org/10.5546/ aap.2021.eng.224

E-mail address:

Carolina Percul, M.D.: carolina.percul@ hospitalitaliano.org.ar

Funding:

None.

Conflict of interest:

None.

Received: $12-8-2020$

Accepted: 2-18-2021 et al. Impact of the COVID-19 pandemic on the pediatric population with acute appendicitis: Experience at a general, tertiary care hospital. Arch Argent Pediatr 2021;119(4):224-229.

\section{INTRODUCTION}

Acute appendicitis is the leading cause of surgical acute abdomen in the pediatric age. In spite of its high incidence, diagnosis may be a challenge in children due to their relative inability -depending on ageto describe and refer symptoms, associated with a lower specificity. ${ }^{1}$

Among patients with acute abdomen due to appendix inflammation, the treatment of choice is appendectomy, which in our setting is usually performed via the laparoscopic approach. This is associated with a shorter length of stay and a lower level of pain and rate of complications after surgery in relation to the traditional surgical approach. ${ }^{2,3}$

However, the new coronavirus disease (COVID-19) pandemic mandated the reassessment of traditional management algorithms. Several recent publications have described experiences from worldwide sites where the usual management was modified to reduce the length of stay, prevent the intubation and anesthesia necessary during surgery,,$^{4-7}$ reduce surgical times, and favor the conventional approach due to an alleged lower virus aerosolization. ${ }^{8-11}$

On March 20 ${ }^{\text {th }}, 2020$, Argentina established a preventive and mandatory social isolation policy. From that moment, the number of visits to the Pediatric Emergency Department dropped abruptly. This led to the hypothesis of a potential change in the characteristics of patients with acute appendicitis: a 
longer delay in consultation and, therefore, a higher incidence of complicated conditions and/ or advanced stages, a higher rate of postoperative complications, and a longer length of stay. ${ }^{9,12-15}$

To date, no national reports have been published about diseases not related to coronavirus, such as acute appendicitis, during the strict lockdown period. This study analyzes the impact of the COVID-19 pandemic on our population of pediatric patients with surgical acute abdomen secondary to acute appendicitis during the strict lockdown period.

\section{POPULATION AND METHODS}

This was a retrospective, analytical study. The study population included all patients younger than 18 years seen at a tertiary care teaching hospital (Hospital Italiano de Buenos Aires) who were diagnosed with acute appendicitis between 03-20-2020 and 08-20-2020 and in the same period in 2019. Patients referred to other facilities for treatment and those diagnosed with acute abdomen secondary to conditions other than appendicitis were excluded.

The following variables were analyzed: population demographics, consultation-related variables (symptoms and time since symptom onset, supplementary tests performed), disease stage (based on what surgeons noted in the surgical report and the subsequent pathological study), surgical approach, length of stay, and postoperative complications.

Appendicitis was diagnosed at both Emergency Departments of the hospital (located in the Autonomous City of Buenos and San Justo, province of Buenos Aires) based on clinical and laboratory data and, in some cases, an ultrasound and / or computed tomography. In our site, the management algorithm was modified with the introduction of preoperative COVID-19 testing, performed by polymerase chain reaction (PCR) of nasopharyngeal swabs, as long as the patient's clinical condition allowed waiting for results. In order to prevent a potential aerosolization of viral particles via the pneumoperitoneum, the laparoscopic approach was exclusively reserved for COVID-19 negative patients; open surgeries were done in positive patients or those in whom results could not be awaited. No patient received an exclusive medical treatment or was discharged with suspected appendicitis.

The study was approved by the Research Protocol Ethics Committee on 10-1-2020 under number 5794. No informed consent was obtained because this was a retrospective study.

With approximately 15 appendectomies performed each month, the sample size was estimated at 150 surgeries in both periods, so the power for a two-tailed test for independent proportions with an 0.05 alpha was estimated. In the descriptive analysis, quantitative data were expressed as mean and standard deviation (SD) or as median and range, based on data distribution. Qualitative data were described as absolute and relative frequency. Comparisons between periods were done using a $\chi^{2}$ test or Fisher's test, based on assumptions for qualitative data, and a t test or a Wilcoxon test for quantitative data, based on data distribution. A $p$ value $\leq 0.05$ was considered the threshold for statistical significance. The statistical analysis was performed with the R software, version 4.0.2.

\section{RESULTS}

A total of 117 pediatric patients seen in both studied periods were analyzed. Of these, 50 patients were from the period between 0320-2020 and 08-20-2020, corresponding to the COVID-19 lockdown. The remaining 67 patients corresponded to the same period of 2019, and made up the control group. Patient distribution by month was equivalent in both periods with a lower number of patients during the pandemic period (Figure 1).

The mean and standard deviation (SD) for age was 11.5 years ( $11.8 \pm 4$ during the pandemic, and $10.8 \pm 3$ the previous year) $(p=0.649)$. Distribution by sex was homogeneous, with a ratio of $52 \%$ males $(26 / 50)$ and $55 \%$ females $(37 / 67)$ during and after the pandemic, respectively $(p=0.874)$. Among studied patients, the percentage of members who were directly affiliated to the Hospital Italiano health insurance program was similar in both periods: $40 \%(27 / 67)$ in 2019 and $38 \%$ (19/50) in 2020; the remaining patients had coverage from workers' unions health insurance organizations and private health insurance companies.

In relation to patients' clinical presentation, the median time since symptom onset until consultation to the Emergency Department was 24 hours in both periods (range: 4 hours- 4 days in 2019 and 3 hours-5 days in 2020) ( $p=0.989)$. The clinical presentation of patients at the time of consultation is described in Table 1.

Peritonitis was observed in $44 \%(\mathrm{n}=22)$ of patients during the pandemic versus $37 \%$ $(\mathrm{n}=22)$ in $2019(p=0.59)$. Figure 2 shows a plot of 
intraoperative findings corresponding to the stage of appendicitis based on the surgical report made by the surgeon in charge of each case.

Surgical exploration was performed in all patients with clinical suspicion, and supplementary tests were done for acute appendicitis. No patient was managed conservatively with antibiotics only. In the period before the pandemic, a laparoscopic approach was the choice in all cases $(67 / 67)$. During the pandemic, a laparoscopy was performed in 21 patients with a negative COVID-19 test before surgery $(42 \%)$. In this period, the mean duration

FIGURE 1. Distribution of patients by month in the study and control periods

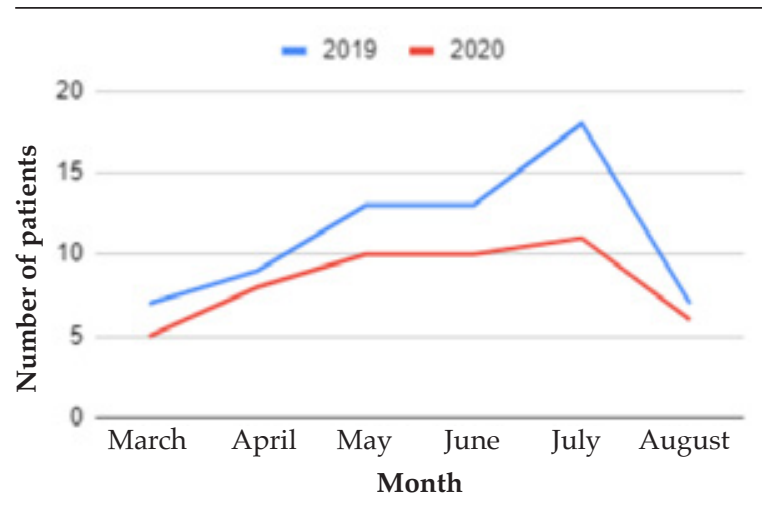

of laparoscopic surgery was 82 minutes (SD: 28). A conventional appendectomy was done in 28 patients without a COVID-19 test before surgery $(56 \%)$ and in 1 positive patient $(2 \%)$, and the procedure lasted a mean of 58 minutes (SD: 17). The time since admission until surgery initiation was 8 hours (SD: 4) in the 2019 period and 11 hours (SD: 5) in 2020, after the implementation of the pre-surgery COVID-19 test.

The clinical course of patients showed that, in both studied periods, the average length of stay was 3 days ( \pm 2 days), antibiotic therapy lasted 7 days (SD: 4 ) with a mean of 3 days (SD: 1.9) of IV antibiotic administration. In patients who underwent laparoscopy, the mean time to food reintroduction was 26 hours (SD: 13.6) and the average length of stay was 3 days (SD: 2), whereas those who underwent a conventional procedure attempted oral tolerance induction at 34 hours (SD: 28.7) and their average length of stay was 4 days (SD: 1.8). Such differences were not statistically significant.

During the first month after surgery, the rate of complications was $6 \%(3 / 50)$ in the pandemic period and $7.5 \%(5 / 67)$ in the control period $(p=0.75)$. Although most complications were mild, e.g., medically treated surgical wound infection, two patients required a revision surgical exploration during the 2019 period (due to intra-

TABLE 1. Clinical presentation of patients at the time of consultation

\begin{tabular}{|c|c|c|c|c|}
\hline Clinical presentation & $\begin{array}{c}\text { Total } \\
(n=117)\end{array}$ & $\begin{array}{l}\text { Control period } \\
\qquad(n=67)\end{array}$ & $\begin{array}{c}\text { Study period } \\
\text { (COVID-19 pandemic) } \\
(\mathrm{n}=50)\end{array}$ & $p$ value \\
\hline $\begin{array}{l}\text { Time to consultation in hours } \\
\text { (median, range) }\end{array}$ & $24(3-120)$ & $24.00(4-96)$ & $24(3-120)$ & 0.989 \\
\hline Abdominal pain & $117(100 \%)$ & $67(100 \%)$ & $50(100 \%)$ & 0.001 \\
\hline Vomiting & $65(55.6 \%)$ & $39(58.2 \%)$ & $26(52 \%)$ & 0.631 \\
\hline Fever & $30(25.6 \%)$ & $17(25.4 \%)$ & $13(26 \%)$ & 0.930 \\
\hline Diarrhea & $18(15.4 \%)$ & $10(14.9 \%)$ & $8(16 \%)$ & 0.870 \\
\hline Leukocytes (median, IQR) & 15050 (12 700-18 108) & 15000 (12 700-17 941) & 15200 (13 202-18 175) & 0.521 \\
\hline $\begin{array}{l}\text { Ultrasound compatible } \\
\text { with appendicitis (among all } \\
\text { patients with ultrasound) }\end{array}$ & $76 / 112(67.9 \%)$ & $41 / 66(62.1 \%)$ & $35 / 46(76.08 \%)$ & 0.119 \\
\hline $\begin{array}{l}\text { Computed tomography } \\
\text { compatible with appendicitis } \\
\text { (among all patients with } \\
\text { computed tomography) }\end{array}$ & $4 / 5$ & $2 / 3$ & $2 / 2$ & 0.363 \\
\hline
\end{tabular}

IQR: interquartile range. 
abdominal collection and intestinal obstruction because of adhesions) with a subsequent favorable course. No patient required a revision surgery in the pandemic period.

\section{DISCUSSION}

In recent months, different medical facilities worldwide published articles about their experience in relation to the clinical presentation of emergency conditions not related to COVID-19, such as acute appendicitis, both in children and adults. The outcomes vary greatly. Some sites described a reduction in the number of cases, which was associated with a lower number of consultations to emergency departments. ${ }^{12,16}$ In other groups, it was observed that, in this period, consultations were delayed due to reasons other than coronavirus infection, which was associated with a higher rate of perforated, complicated appendicitis. ${ }^{13}$ In our site, no significant differences were observed in terms of time to consultation since symptom onset or based on the stage of the disease. However, the total number of patients seen with acute appendicitis during the pandemic period reduced by $25 \%$. Such difference may be due to the relatively low number of cases and is not necessarily directly related to the epidemiological situation. Also, it is worth noting that the study was carried out in a private hospital that caters only patients with coverage from workers' unions health insurance organizations and private health insurance companies. The experience in a public health system may be different.
In relation to clinical manifestations, patients analyzed in both periods presented with mainly gastrointestinal symptoms. The increasing knowledge about COVID-19 suggests that these may be the initial symptoms (sometimes, even the only symptoms observed) of SARS-CoV-2related multisystem inflammatory syndrome, a condition with systemic inflammation and multiple organ failure caused by the virus. ${ }^{17} \mathrm{~A}$ study conducted in 44 pediatric patients described the presence of gastrointestinal symptoms in $84 \%$ of patients, and $75 \%$ had no severe respiratory symptoms. Reports have also demonstrated a higher frequency of gastrointestinal symptoms in pediatric patients with COVID-19 compared to adults. ${ }^{18}$ This way, coronavirus infection should be included in the differential diagnosis of patients presenting with acute abdomen, and each case should be assessed individually.

Thanks to the rapid dissemination of information in this context, countries affected by the pandemic prior to the epidemic peak in Argentina published their experience about the incidence of COVID-19 and in relation to surgeryspecific technical aspects. Other publications describe the risks and benefits of a laparoscopic approach. Authors who do not suggest using this technique argue that it may increase the aerosolization of viral particles and surgery duration, which would, in turn, result in a greater exposure of health care staff to a higher risk for infection. ${ }^{19,20}$ In favor of the laparoscopic approach, there is not enough reliable evidence about virus aerosolization and it is associated

FIGURE 2. Intraoperative appendicitis findings in each period

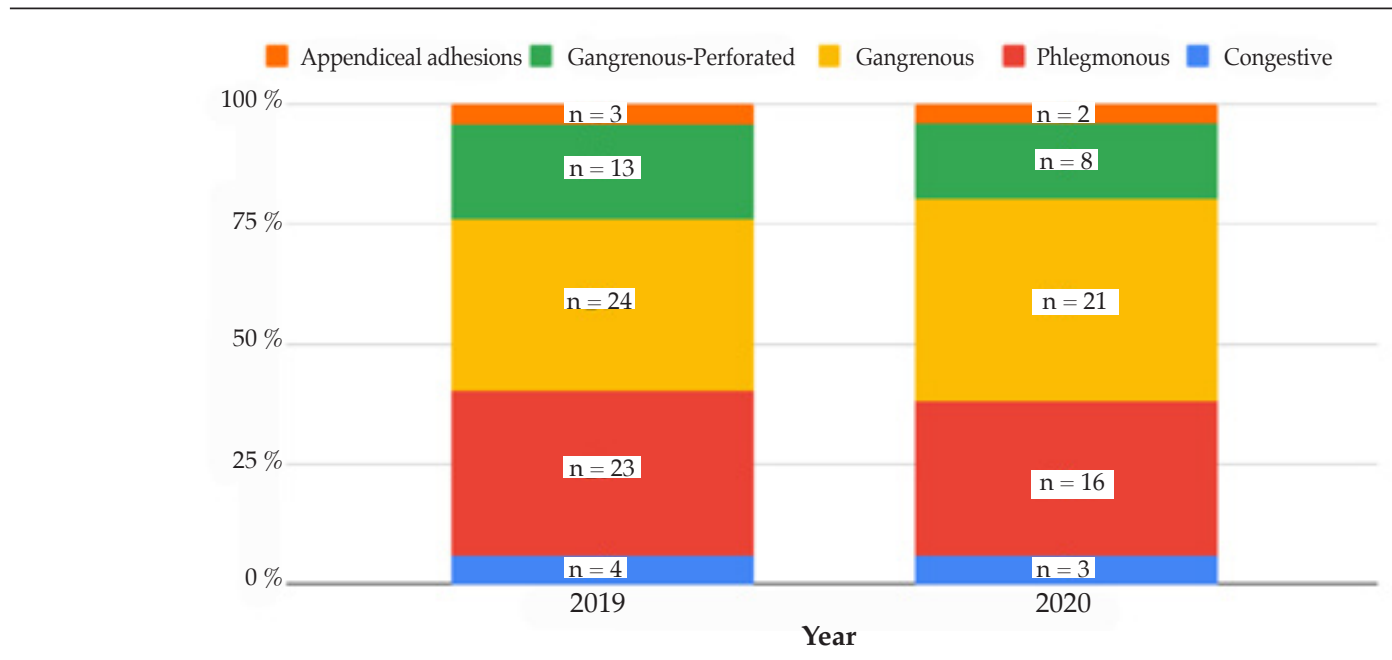


with a shorter length of stay, with a reduced risk for intra-hospital infection among patients during hospitalization. ${ }^{21}$ Due to the lack of clinical trials, most information is extrapolated from prior experiences with other viruses or pathogens. Based on previously obtained information, in our site, the laparoscopic approach has been reserved exclusively for COVID-19 negative patients prior to surgery. Patients with a positive or unknown result undergo an open surgery in the hands of the most experienced surgeon available, so as to reduce the surgical time. This has translated into a significant increase in the number of open appendectomies, which were the exception in our site before the pandemic.

The comparison of patients based on the surgical approach showed that the procedure was shorter in patients undergoing an open surgery compared to a laparoscopy; and no significant differences were observed in terms of length of stay, food reintroduction or antibiotics and analgesics requirement between both groups.

To our knowledge, this is the first study about the incidence and presentation in pediatric patients with acute appendicitis during the pandemic in Argentina. This is the experience in a general, tertiary care, private hospital which, although it works as a referral facility for patients at a regional and national level, accounts for only one sector of the health care system. In addition, a limitation of this study is its retrospective nature.

\section{CONCLUSIONS}

Although the number of acute appendicitis cases in the pediatric population was lower during the study period, in our hospital, no significant impact was observed in terms of clinical presentation and severity. To date, the surgical approach, avoiding a laparoscopic procedure to reduce virus transmission, appears to be the most significant change resulting from the pandemic.

\section{REFERENCES}

1. Glass CC, Rangel SJ. Overview and diagnosis of acute appendicitis in children. Semin Pediatr Surg. 2016;25(4):198203.

2. Biondi A, DiStefano C, Ferrara F, Bellia A, et al. Laparoscopic versus open appendectomy: A retrospective cohort study assessing outcomes and cost-effectiveness. World J Emerg Surg. 2016; 30;11(1):44.

3. Brügger L, Rosella L, Candinas D, Güller U. Improving outcomes after laparoscopic appendectomy: A populationbased, 12-year trend analysis of 7446 patients. Ann Surg. 2011; 253(2):309-13.
4. Kvasnovsky CL, Shi Y, Rich BS, Glick RD, et al. Limiting hospital resources for acute appendicitis in children: Lessons learned from the U.S. epicenter of the COVID-19 pandemic. J Pediatr Surg. 2020; S0022-3468(20)30444-9 [In press].

5. Collard M,LakkisZ, Loriau J, Mege D, etal. Antibiotics alone as an alternative to appendectomy for uncomplicated acute appendicitis in adults: Changes in treatment modalities related to the COVID-19 health crisis. J Visc Surg. 2020; 157(3S1):S33-42.

6. Jones BA, Slater BJ. Non-operative management of acute appendicitis in a pediatric patient with concomitant COVID-19 infection. J Pediatr Surg Case Rep. 2020;59:101512.

7. VermaS, Garg P, Verma A, Sirohi V. Careful Non-operative Management with Surveillance of Acute Appendicitis During COVID-19 Pandemic. Indian J Surg. 2020;1-2. [In press]

8. Scott C, Lambert A. Managing appendicitis during the COVID-19 pandemic in the UK. Br J Surg. 2020; 107(8):e271.

9. Dreifuss NH, Schlottmann F, Sadava EE, Rotholtz NA. Acute appendicitis does not quarantine: surgical outcomes of laparoscopic appendectomy in COVID-19 times. $\mathrm{Br} \mathrm{J}$ Surg. 2020; 107(10):e368-9.

10. Ngaserin SHN, Koh FH, Ong BC, Chew MH. COVID-19 not detected in peritoneal fluid: a case of laparoscopic appendicectomy for acute appendicitis in a COVID-19infected patient. Langenbecks Arch Surg. 2020; 405(3):353-5.

11. Wexner SD, Cortés-Guiral D, Gilshtein H, Kent I, et al. COVID-19: impact on colorectal surgery. Colorectal Dis. 2020; 22(6):635-40.

12. Velayos M, Muñoz-Serrano AJ, Estefanía-Fernández K, Sarmiento Caldas MC, et al. Influencia de la pandemia por coronavirus 2 (SARS-Cov-2) en la apendicitis aguda. An Pediatr (Barc). 2020; 93(2):118-22.

13. Snapiri O, Rosenberg Danziger C, Krause I, Kravarusic D, et al. Delayed diagnosis of paediatric appendicitis during the COVID-19 pandemic. Acta Paediatr. 2020; 109(8):16726.

14. English W, Habib Bedwani N, Smith C, Shatkar V. Investigation and management of suspected appendicitis during the COVID-19 pandemic. Br JSurg. 2020; 107(9):e3378.

15. Romero J, Valencia S, Guerrero A. Acute Appendicitis During Coronavirus Disease 2019 (COVID-19): Changes in Clinical Presentation and CT Findings. J Am Coll Radiol. 2020; 17(8):1011-3.

16. ZvizdicZ, VranicS. Decreased number of acute appendicitis cases in pediatric population during the COVID-19 pandemic: Any link? J Pediatr Surg. 2020; 56(1):199-200.

17. Bolia R, Ranjan R, Bhat NK. Recognising the Gastrointestinal Manifestation of Pediatric Coronavirus Disease 2019. Indian J Pediatr. 2020; 88(1):101-2.

18. Miller J, Cantor A, Zachariah P, AhnD, etal. Gastrointestinal Symptoms as a Major Presentation Component of a Novel Multisystem Inflammatory Syndrome in Children That Is Related to Coronavirus Disease 2019: A Single Center Experience of 44 Cases. Gastroenterology. 2020;159(4):15714.e2.

19. Polites SF, Azarow KS. Perspectives on Pediatric Appendicitis and Appendectomy During the Severe Acute Respiratory Syndrome Coronavirus 2 Pandemic. J Laparoendosc Adv Surg Tech A. 2020; 30(4):356-7.

20. Zheng $\mathrm{MH}$, Boni L, Fingerhut A. Minimally Invasive Surgery and the Novel Coronavirus Outbreak: Lessons Learned in China and Italy. Ann Surg. 2020; 272(1):e5-6. 
Impact of the COVID-19 pandemic on the pediatric population with acute appendicitis: Experience at a general, tertiary care hospital / 229

21. Montalva L, Haffreingue A, Ali L, Clairot S, et al. The role of a pediatric tertiary care center in avoiding collateral damage for children with acute appendicitis during the COVID-19 outbreak. Pediatr Surg Int. 2020;36(12):1397-405. 